\title{
Instrumentos de voice giving na relação entre os cidadãos e a administração pública: a carta dos serviços*
}

\section{Introdução}

O sistema da administração pública italiano foi sempre caracterizado por prevalecer uma lógica de processo, fundada na tecnologia ou no produto, antes que em uma lógica de serviço particularmente atenta às exigências sócio-econômicas dos cidadãos. De fato, às mudanças sócioeconômicas e tecnológicas que interessam ao ambiente de mercado no qual a administração pública se encontra e opera, não se seguiu um correspondente processo de adequação das instituições públicas, determinando assim, um progressivo distanciamento entre as atividades colocadas em prática pela administração pública e as novas exigências da sociedade (Mele, 1994).

Tal fenômeno tem sido acentuado pela persistência de uma tradicional distância entre os usuários dos serviços públicos e os entes fornecedores desses serviços. Em outras palavras, os cidadãos são considerados usuários ${ }^{1}$ dos serviços, porque não se reconhecem no papel de proprietários dos mesmos. A mesma estranheza mostrada com relação à gestão da res publica acentuou a incompreensão por parte da sociedade da missão pública, sobretudo porque tem-se mostrado pouco disponível a reconhecer nos cidadãos a titularidade do serviço público.

Deste modo, com o objetivo de observar a relação entre os cidadãos (proprietários dos serviços públicos) e os administradores de organizações e empresas de serviços públicos (prestadores do serviço e, portanto, agentes do mandato constitucional de realizar o objetivo de atender aos interesses sócio-econômicos da sociedade), e de analisar o modo no qual os respectivos interesses divergem ou convergem entre si, serão utilizadas,

Salvatore Esposito de Falco é doutor em pesquisa de Doutrinas

Econômico-

Empresariais

e Direção de

Empresas, no Instituto Universitário

Naval de

Nápoles e pós-doutorando na Faculdade de

Economia da Universidade de Estudos de Salerno.

Contato: azienda.pubblica@ $\underline{\text { unibocconi.it }}$

Traduzido por Helena Sgarbi 
no presente trabalho, as perspectivas de investigação da teoria do agente principal e dos stakeholders. Farei uso dessas teorias por serem mais adequadas para destacar as discrepâncias de interesses delineadas entre as partes, fornecendo indicações instrumentais úteis para realinhar o relacionamento entre cidadãos e administradores das organizações e empresas de serviços públicos. Em particular, enquanto a teoria do agente principal parece útil, no sentido descritivo, para individualizar os atores e as recíprocas relações que caracterizam a organização interna da administração pública, a teoria dos stakeholders — definindo um modelo para o exame das conexões entre os atores (stakeholders) e a obtenção dos vários objetivos de performance - favoreceu, de modo prescritivo $^{2}$, a utilização de modelos de gestão que, enquanto atentos aos interesses legítimos de todos os stakeholders, favorecem a implementação de um sistema empresarial orientado ao valor.

Nesse sentido, a diretriz da Presidência do Conselho dos Ministros de 22 de fevereiro de 1994, que introduziu a carta dos serviços públicos, parece uma tentativa revolucionária voltada a restabelecer a relação original (direta) entre os cidadãos e o administrador das empresas de serviço público, além de estimular, nos primeiros, a consciência de exercer um papel ativo dentro do sistema público, e nos últimos, uma consciência simultânea dos interesses legítimos de todos os stakeholders, seja na definição das estruturas organizacionais e das políticas gerais, seja, caso a caso, no processo decisório.

Partindo de tais considerações, no presente trabalho, a carta dos serviços foi revista como instrumento de voice giving, ${ }^{3}$ dado que, por um lado, fornece aos cidadãos meios necessários para monitorar e controlar as atividades públicas e, por outro, representa um útil mecanismo de regulamentação e coordenação das atividades econômicas para as empresas de serviço público, que poderão fornecer serviços mais coerentes com as expectativas dos cidadãos.

\section{Recomposição da res publica e nascimento de novos atores sócio-institucionais: principais, agentes e stakeholders}

A crescente insatisfação até agora demonstrada pelos cidadãos relacionada à gestão dos serviços públicos deve-se, pelo menos em parte, à consolidada presença de uma assimetria de informações entre os atores do sistema sócio-econômico (instituições, cidadãos, empresas) que, inevitavelmente, obstaculiza a coordenação entre as instâncias dos cidadãos e as atividades das empresas de serviço público. Nesse sentido, o cidadão possui pouquíssimas informações, insuficientes tanto em termos 
qualitativos quanto quantitativos, para observar as atividades exercidas pela administração pública.

A observação do comportamento dos administradores públicos tornou-se difícil devido à falta de instrumentos precisos de avaliação das performances empresariais, além de instrumentos de comunicação e de voice giving, determinando, assim, um distanciamento entre as exigências dos cidadãos e a oferta dos serviços públicos.

Para efetuar uma atenta avaliação das inter-relações existentes entre cidadãos e administração pública, utilizou-se a teoria do agente principal e a teoria dos stakeholders, com a finalidade de, por um lado, individualizar os atores e os relativos papéis relacionais e, por outro, identificar um sistema de gestão e organização, de modo a reduzir a distância entre administradores públicos e cidadãos e garantir uma melhoria dos objetivos públicos.

Com referência ao primeiro ponto e deixando de lado momentaneamente a idéia dos stakeholders, na interpretação da res publica, a relação do agente principal é definida como uma "forma de interação social" (Ross, 1973) na qual se determina uma gama de contrato bilateral, pelo qual o principal delega ao agente o desenvolvimento de uma tarefa por conta própria, disponibilizando ao mesmo uma recompensa externa ou interna e conferindo-lhe a necessária autonomia de ação.

Sob tal ótica, o público principal é representado por qualquer centro decisório com poder para criar órgãos deliberativos formalmente estabelecidos pela Constituição. Desse modo, o centro em questão define o direcionamento estratégico da gestão empresarial pública e estabelece as prioridades de realização dos objetivos pré-fixados. $\mathrm{O}$ agente, por outro lado, é um sujeito controlado, no sentido em que é escolhido pelo principal e oferece suas atividades de modo a atingir fins preestabelecidos por este (Cafferata e Caselli, 1995).

Deve-se, todavia, observar que, com base em tal interpretação das relações de poder entre o principal e o agente público, evidencia-se a troca de posições de papéis. Viu-se, de fato, que os cidadãos, como EstadoComunidade, podem ser considerados principal em relação àqueles que agem com base nos seus interesses (a satisfação das necessidades sociais), e que, em tal caso, são os órgãos do Estado a representar a sociedade, que demanda o exercício de Poder Legislativo e, indiretamente, Executivo e Judiciário. Segundo tal interpretação, o Estado-Comunidade é o principal do Estado-Aparato ou institucional. ${ }^{4}$

Pressupõe-se, portanto, que a relação do agente seja estendida ao relacionamento entre os cidadãos (no papel de principal) e a direção das empresas de serviço público (como agente). Tal consideração é válida na medida em que os administradores das empresas de serviço público possuem as justas competências profissionais para o desenvolvimento das próprias funções. A estes, o cidadão confere uma substancial discricionariedade, 
contando com a possibilidade de exprimir um juízo (consenso - discenso) sobre seus feitos com o voto (Baccarani, 1992).

$\mathrm{Na}$ realidade, a persistente assimetria de informações, e a falta de instrumentos capazes de medir as performances empresariais e de ativar um processo de comunicação entre os atores do sistema, impedem que o cidadão julgue o trabalho dos administradores públicos, e que venha a modificar a cadeia/ciclo do agente que, de fato, governa as escolhas dos administradores públicos, acabando por enfraquecê-las ou comprometendo-as definitivamente (Baccarani, 1988).

Em outras palavras, depois de os cidadãos terem delegado indiretamente aos administradores públicos (por meio do voto) a gestão das atividades públicas, não se consegue mais controlar o funcionamento das mesmas por falta de instrumentos informativos adequados e por obter informações incompletas, além da impossibilidade de escolher o fornecedor mais eficiente (explicitamente neste sentido, o cidadão não pode ser considerado cliente da administração pública, porque não pode escolhêla, nem mudá-la). ${ }^{5}$

A afirmação e a consolidação de tais situações determinaram na sociedade uma "perda de consciência" do próprio papel institucional, acabando, com o tempo, por autorizar o administrador das empresas de serviços públicos a valer-se de uma gama de "legitimação por dogma", como se possuíssem um direito absoluto de existir como instituições superiores, com respeito às quais não cabe procurar motivos de racionalidade técnica e econômica (Baccarani, 1992).

Como reflexo, os cidadãos são levados a repudiar o princípio da perfeição do agir público e a confrontar a legitimação social das empresas públicas com aquelas do setor privado.

Nesse sentido, observou-se que a maior eficiência da administração das empresas privadas deve ser conectada sobretudo ao fato de que os administradores privados devem prestar contas aos proprietários acionistas dos seus atos, objetivando o retorno das remunerações dos capitais investidos.

Nas empresas de serviço público, por outro lado, o controle exercido pelos cidadãos sobre os administradores públicos é extremamente diluído e pouco eficaz: como se poderá observar mais difusamente, a assimetria de informação afasta os cidadãos do seu papel de principal, relegando-os àquele de simples usuários dos serviços públicos.

Essa notável diferença, em termos de prioridade/responsabilidade da gestão, "determinou no setor privado, escolhas mais focadas e melhor projetadas para a eficiência/eficácia da gestão, enquanto no setor público deu origem a um relaxamento geral por parte dos responsáveis, que não precisam prestar contas de seu exercício, já que outro (finança estatal) providencia o seu saneamento" (Pellicano, 1995). ${ }^{6}$ 
É possível afirmar, desse modo, que a relação entre principais e agentes públicos parece fortemente desequilibrada, principalmente pelos seguintes motivos:

- forte conflito de interesses entre os cidadãos (no papel de principal) e os administradores das empresas de serviços públicos (no papel de agentes); os primeiros forçam o melhoramento da qualidade dos serviços públicos, enquanto os últimos tentam reduzir os esforços destinados a alcançar tal objetivo;

- forte aversão ao risco por parte dos agentes (os administradores públicos), que obstaculizam a mudança e o esforço nessa direção, mudança fortemente desejada, por outro lado, pelo principal (os cidadãos), por não estar satisfeito com os serviços;

- os cidadãos, não suficientemente conscientes do próprio papel de proprietários da res publica, não percebem o risco dentro da mudança e não são conscientes de seu papel, no sentido de induzir o agente a comportamentos mais inovadores;

- os administradores públicos, não reconhecendo nos cidadãos a figura do principal, não parecem dispostos a incrementar os próprios esforços em direção às solicitações deles;

- ausência de eficientes/eficazes instrumentos institucionais de controle direto sobre os administradores públicos por parte dos cidadãos;

- consciência do agente da própria autonomia e da ineficácia do controle por parte dos cidadãos, com conseqüente atenção à realização dos objetivos por ele mesmo programados e da satisfação não dos cidadãos, mas do referente político;

- o referente político, por fim, descarrega sobre o administrador público a responsabilidade das ineficiências, já que não há nem controle nem sanção por parte dos cidadãos.

\section{O difícil papel do principal e a co-presença dos stakeholders públicos}

Na presença de uma relação principal/agente público fortemente desequilibrada e na ausência de instrumentos em grau de controlar a atuação dos administradores, a distância entre os cidadãos e a administração pública acentuou, gerando um sistema relacional no qual a comunicação é sempre mais comprometida pela presença de diferentes figuras intermediárias que, como veremos melhor em seguida, dependendo do ângulo visual, assumem o papel de subprincipal ou subagente, ou seja, sob uma ótica ampla, a dos stakeholders.

Em suma, o sistema público parece composto por um conjunto de unidades autônomas distintas (Borgonovi, 1996): 
- órgãos políticos, ou de governo, constituídos principalmente pelos entes (ou institutos) territoriais públicos. Estes representam o poder originário da comunidade eletiva (entes exponenciais), exprimindo o nível de centralização e descentralização da organização estatal (distribuição vertical) em múltiplas funções (entes plurifuncionais);

- órgãos executivos, constituídos por órgãos técnico-operacionais, ou seja, agências e empresas autônomas. Tais órgãos são nomeados pelos entes públicos territoriais e exercitam, por conta destes, funções limitadas (entes monofuncionais), exprimindo o nível de diversificação da intervenção pública (distribuição funcional horizontal);

- empresas públicas, caracterizadas pelas mesmas peculiaridades dos órgãos executivos, operam no mercado, perseguindo uma vontade própria e autônoma de sobrevivência no respeito das condições de economicidade.

Privilegiando um critério de classificação que compreenda a natureza e a amplitude dos poderes reconhecidos pelos órgãos do setor público e as relações que ocorrem entre eles, pode-se com certeza acreditar que a funcionalidade e a eficiência do mesmo dependem do conjunto de relações que se estabelecem entre as unidades do sistema, que por sua vez, dependem da dinâmica contextual dos sistemas institucionais (conhecimentos, competências, profissionalismo, interpretação das leis, comportamentos políticos atuais etc.). Portanto, o conjunto das relações indicadas pode ser revisto sob a ótica da teoria do agente principal, cuja interpretação seqüencial dos vínculos públicos une os vários componentes do conjunto institucional com base nos possíveis papéis assumidos enquanto agente (Fig.1).

A citada concatenação gera uma estrutura articulada em série, na qual cada anel da sucessão assume — simultaneamente - o papel do principal e do agente. Dessa maneira é falseada a ligação institucional originária que denomina os órgãos políticos como entes exponenciais da comunidade, representantes dos poderes originários dos cidadãos por delegação política.

Nesse sentido, o poder soberano é delegado a outros órgãos que se difundem ao longo da cadeia de agentes, gerando, assim, uma dispersão da delegação dos poderes finais à composição dos interesses coletivos e acentuando, por outro lado, a distância entre o verdadeiro principal (os cidadãos) e o verdadeiro agente (o administrador das empresas de serviços públicos).

Seguindo essa perspectiva de análise, a utilização da teoria do agente principal parece útil para observar as características e os comportamentos dos atores sócio-institucionais na relação cidadãos/administração das empresas de serviço público. Em particular, ainda que tal aproximação metodológica tenha uma natureza tipicamente prescritiva, já que individualiza modalidades específicas de governo das relações ${ }^{7}$, no presente 
trabalho, assume uma configuração descritiva, enquanto é voltada principalmente a fotografar a distância relacional intercorrente entre os administradores das empresas dos serviços públicos e os cidadãos.

Figura 1: A cadeia principal/agente da relação cidadãos/administração pública

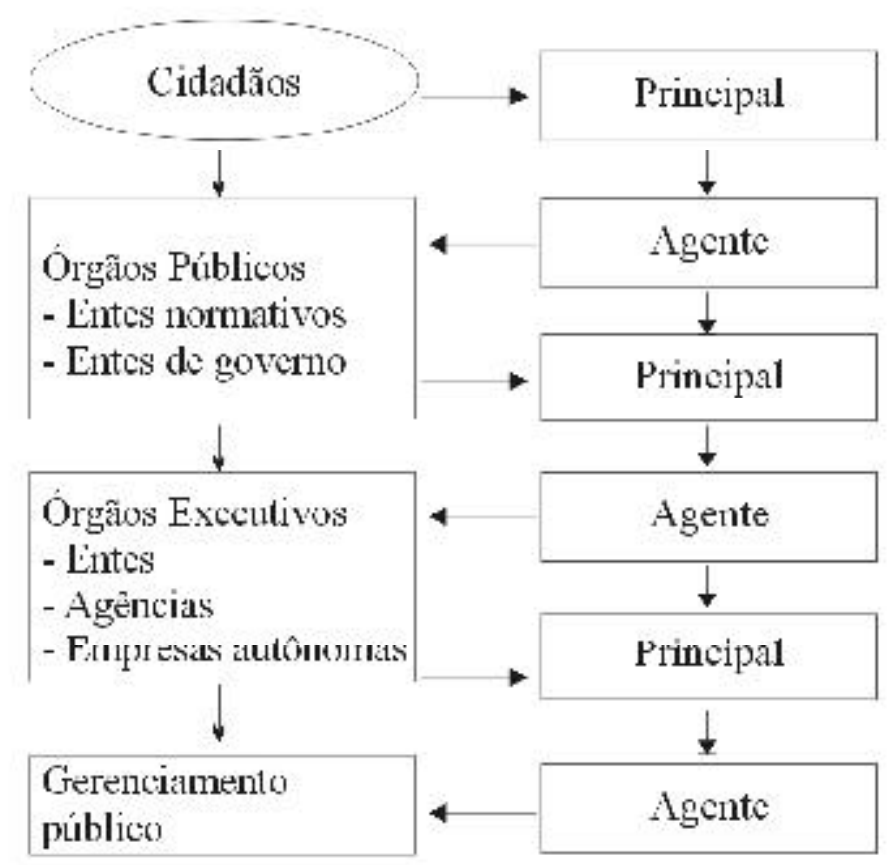

A utilização da perspectiva da teoria do agente principal somente em forma descritiva justifica-se pela presença de uma relação que envolve, por um lado o administrador das empresas de serviço público, e, por outro, os cidadãos, onde o grau de satisfação fundamenta-se principalmente nas necessidades sociais, morais, de auto-organização e no melhoramento do estado de bem-estar social.

Devemos destacar que o recurso conceitual da teoria do agente principal oferece uma visão plenamente reificada ${ }^{8}$ da empresa, pública ou privada, exaltando o aspecto legal e contratual. Em outras palavras, na perspectiva da teoria do agente principal “... a organização se desvincula da subjetividade do empreendedor e é exaltada a pura objetividade da estrutura...". Portanto, permanecem não observados o aspecto humano e o quadro motivacional que, ao contrário, poderiam dar vida à organização. 
As motivações dos indivíduos, de fato, além de materiais são também morais, e investem na esfera da satisfação das necessidades de autorealização e também naquela da necessidade social de colaboração (Gallinaro, 1996: 344-345). ${ }^{9}$

Portanto, o testemunho da ampliação do raio de ação da gestão da res publica, no presente trabalho, virá favorecer a utilização da teoria dos stakeholders ${ }^{10}$, que interpreta a empresa como “... uma entidade organizacional pela qual numerosos e diferentes participantes alcançam os seus múltiplos objetivos, nem sempre congruentes" (Donaldson e Preston, 1995).

Desse modo, diante da progressiva perda de unidade e de homogeneidade interna do sistema da administração pública, a empresa pública é reinterpretada como uma multiplicidade de centros interagentes, todos em condições de influenciar ao longo do processo decisório; portanto, além do centro - ou seja, dos cidadãos — os outros centros (os órgãos políticos de governo, os órgãos públicos executivos, as empresas de serviços públicos, os sindicatos etc.).

Tal enfoque teórico origina-se na escola neo-institucional que exalta a importância da relação entre as organizações e o ambiente, além daquela entre as instituições e os comportamentos sociais. Com referência a este último ponto, deve-se salientar a contribuição científica de Zucker que, em contraposição à escola funcionalista, coloca a importância determinante das instituições em moldar os comportamentos sociais, afirmando que "para entender verdadeiramente como a ordem social mantém e transmite-se na vida cotidiana, é necessário colocar-se no lugar dos sujeitos e examinar as circunstâncias, os atos discursivos, os contextos cotidianos nos quais as regras são percebidas e transmitidas" (Zucker, 1977). A teoria neo-institucional baseia-se no pressuposto segundo o qual não é possível conhecer uma regra independentemente das práticas que são consideradas, suas diretas aplicações; isso enquanto não há sentido considerar as regras como entidades em si, porque os comportamentos indicados como exemplos do "seguir uma regra" mostram o significado daquela regra para os sujeitos que a seguem (Bonazzi, 1995: 453-454).

De modo especulativo, a teoria dos stakeholders confere explícito reconhecimento aos interlocutores sócio-econômicos e institucionais para a vida da empresa - privada ou pública - e reaviva as relações recíprocas com os grupos e os indivíduos portadores de interesses “...com o fim de elaborar uma série de decisões e colocar em prática uma série de ações concretas para a satisfação das suas expectativas..." (Freeman, 1984). Adotando um comportamento tipicamente neo-institucional, a teoria dos stakeholders considera a realidade como uma construção social, na qual os objetos deduzidos da experiência cotidiana não são independentes dos métodos com os quais se observam e se compreendem. Portanto, a teoria dos stakeholders indica como critério gerencial de condução das 
relações sociais um enfoque puramente relacional, baseado na confiança e na completa abertura a todos os interlocutores empresariais (primários e secundários).

Pelo que foi exposto até aqui, tal concepção poderia parecer contrastante com a visão contratual da empresa, segundo a qual os atores da empresa preferem cooperar no interior da organização por meio do mercado, para minimizar os custos da pesquisa, da coordenação e da insegurança etc.

Ao contrário, parte da doutrina e principalmente Hill e Jones (1992) afirmam que o enfoque da teoria do agente principal pode ser integrado com aquele dos stakeholders, de modo a considerar os agentes da relação como agentes de todos os stakeholders. Nesse sentido, no presente trabalho, todos os atores da Figura 1 transformam-se em verdadeiros stakeholders (Fig. 2) de um único agente, que é o administrador público.

Figura 2: Mapa dos stakeholders na administração pública

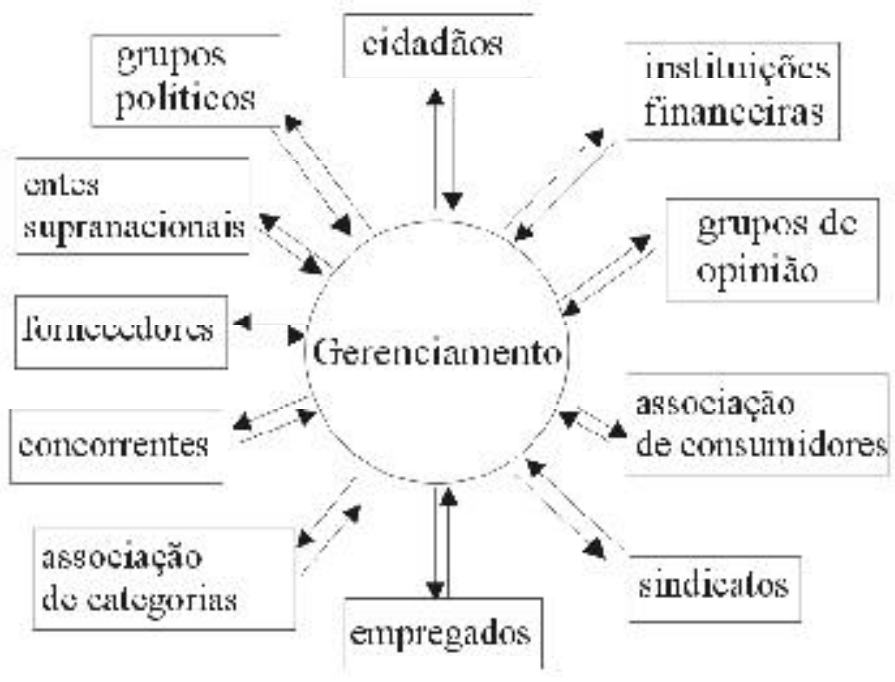

Por tudo isso, a análise tende a se focalizar no processo, na direção e na velocidade de adaptação das relações entre stakeholders e agentes, mais que no conjunto de equilíbrio entre salários e recompensas (Donaldson e Preston, 1995). Em tal sentido, Hill e Jones (1992: 140) opõem-se à concentração dos recursos de controle praticada por parte do administrador e à difusão do controle entre os grupos de stakeholders por meio da própria comunicação. 
A partir da análise conduzida pela teoria do agente principal e pela teoria dos stakeholders, parece evidente a necessidade de otimizar os mecanismos de comunicação, mediante os quais são, se não eliminados, pelo menos reduzidos àquelas aberrações públicas, ou seja, aquelas anomalias que geram desequilíbrios nas inter-relações sócio-institucionais. Tudo isso permitiria a criação de um sistema de empatia relacional que obstaculizaria a formação de eventuais distorções relacionais, tais como assimetrias informacionais, ausência de comunicação horizontal e transversal e falta de uma cultura comum que inevitavelmente favoreceria a ativação de comportamentos oportunísticos.

\section{A carta dos serviços como instrumento de voice giving para a reconciliação entre os cidadãos e a administração pública}

A carta dos serviços públicos deve responder a todas essas exigências, como um documento programático que exprima a vontade de criar uma nova relação entre os cidadãos e a administração pública e que introduza uma metodologia capaz de reorientar o serviço público em direção à demanda ${ }^{11}$, atribuindo aos cidadãos um papel ativo de proprietários do serviço público.

Criada por iniciativa do Ministério da Função Pública, esse instrumento encontrou aplicação normativa na diretriz da Presidência do Conselho dos Ministros, de 22 de fevereiro de 1994. ${ }^{12}$ A iniciativa — que se inspirou em algumas experiências de outros países, principalmente Reino Unido, França e Espanha - objetiva melhorar a eficiência administrativa, deslocando o cidadão para o centro do sistema relacional público. $\mathrm{O}$ objetivo é disponibilizar um documento em condições de comunicar aos cidadãos e à comunidade do público interessado nas organizações (stakeholders) os compromissos de qualidade assumidos.

Com particular atenção, a carta disciplina a relação entre os entes fornecedores de serviço público e os cidadãos, ressaltando particularmente a qualidade dos serviços a serem prestados. Apresenta-se em três partes: os princípios fundamentais, os instrumentos e a tutela.

A primeira parte apresenta os princípios fundamentais nos quais se deve inspirar o fornecimento dos serviços públicos, dando especial atenção àqueles da igualdade, da imparcialidade, da continuidade, do direito de escolha, da participação, da eficiência e da eficácia.

Com relação aos instrumentos (segunda parte), a carta prevê que, por parte dos fornecedores, proceda-se à individualização de padrões de qualidade e de quantidade dos serviços de tipo geral — ou seja, referentes 
ao conjunto dos serviços prestados — ou de tipo específico, em relação a cada um dos serviços em particular, fornecidos ao cidadão. ${ }^{13}$

A terceira parte define os mecanismos de tutela e de garantia para uma correta aplicação da carta. ${ }^{14}$ Para verificar a qualidade do serviço fornecido, os entes prestadores de serviço devem adotar procedimentos específicos.

O documento é inspirado em uma metodologia de monitoramento baseada em uma regulação diversificada dos entes prestadores, fornecedores de serviços públicos, mediante:

- padrões gerais e específicos de serviço;

- avaliações periódicas realizadas pelos entes prestadores;

- coleta das reclamações e intervenções visando à eliminação das distâncias entre padrões e as prestações efetivas de serviços.

Recuperando as considerações teóricas desenvolvidas anteriormente, e utilizando o enfoque do agente principal com objetivos puramente descritivos, a carta dos serviços oferece soluções válidas para descarregar os custos da agência (custos de bonding, conforme nota 7) sobre o agente público, reequilibrando, assim, o conceito de serviço público, passando do mero resultado de uma atividade geral, ao específico e improrrogável direito a ser satisfeito.

Todavia, deve ficar claro que sob essa ótica, o principal (cidadãos) poderia valer-se de controles ex post, recorrendo à avaliação dos resultados, tentando, além disso, reduzir o oportunismo dos agentes públicos, imputando aos mesmos custos específicos de garantia (bonding) (Fig.3).

Figura 3: O mecanismo de realinhamento

das posições de principal e agente na relação entre cidadãos e administração pública

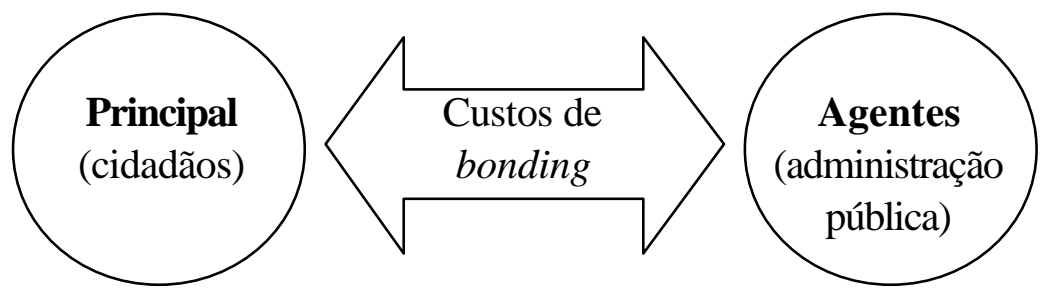

A verdade é que essa tese, que se baseia na persistência da assimetria informacional, tem plena validade: justifica, de fato, o principal público a descarregar sobre o agente público os custos da agência. Desse modo, o agente seria forçado a fornecer garantias sobre a positividade de sua atuação (coerência com os objetivos do principal), submetendo-se a um depósito em dinheiro, bonding, para cobrir os riscos das próprias 
ações, caso sejam adversas ao interesse do principal (Jensen e Meckling, 1976). Tais custos de asseguração (custos de bonding) imporiam ao agente a fixação de determinados padrões a serem respeitados na realização das próprias atividades, sob pena da quebra de contrato e de pagamento de penalidade específica.

Essa perspectiva, anteriormente apresentada, parece restritiva porque se limita à análise dos aspectos econômicos dos custos, negligenciando, por outro lado, aqueles de comunicação, nos quais deve principalmente se inspirar uma relação saudável entre cidadãos e administração pública. Portanto, retomando a teoria dos stakeholders e recuperando os pontos oferecidos por Hirschman, a carta dos serviços apresenta-se como instrumento facilitador da introdução de mecanismos concorrenciais no interior do sistema público do tipo voice giving e/ou exit. No primeiro caso, a carta dos serviços se legitima como instrumento de comunicação institucional, no qual, no centro da mensagem, é colocada a personalidade social da empresa pública, ao invés dos atos ou dos fatos pelo qual esta se exprime (Milanese, 1994). Em tal caso são introduzidos mecanismos de concorrência virtual do tipo "palavra de honra". Como exit, por outro lado, a lista introduz mecanismos concorrenciais do tipo "real", já que mune os cidadãos do poder de "sair da indistinta reclamação, fornecendolhes a oportunidade de medir a qualidade dos serviços obtidos por meio de um sistema de indicadores periódicos, difusos, confrontados e publicados anualmente, tornando possível uma eventual concorrência horizontal entre uma USL (Unidade Sanitária Local) e a outra, uma escola e a outra" (Pellicano, 1995).

No presente trabalho, todavia, a análise limitar-se-á aos mecanismos de voice giving e, portanto, a carta é revista como instrumento que induz os cidadãos à "palavra de honra". Isso favorece, além do mais, a implementação de um sistema de controle e monitoramento das atividades exercidas pelo administrador público, constrangendo-o a subscrever as garantias de segurança sobre a coerência do próprio comportamento.

Chega-se assim a compreender que existem pelo menos três mecanismos de regulamentação das exigências dos stakeholders no sistema da administração pública: um mecanismo econômico, baseado na avaliação da eficiência; um mecanismo político, que funciona como alavanca para o consenso; um mecanismo social, que se baseia nas convenções ou nos costumes. Disso deriva que a comunicação não é somente explicável "pela articulação dos conteúdos nos quais se concentra, mas nasce também e sobretudo das modalidades que levam à definição dos conteúdos" (Milanese, 1994). Em particular no caso da administração pública, onde prevalecem mecanismos de legitimação política, é necessário criar um fluxo de comunicação, ativo e passivo, orientado a transferir e localizar informações. 
Nesse aspecto, a carta dos serviços poderia suprir a, até agora inexistente, verificação constante dos procedimentos colocados em prática pela administração pública, para monitorar a satisfação do cidadão em relação à rigidez do serviço público e para verificar a produtividade e a funcionalidade dos procedimentos executados. De fato, o documento introdutório da carta dos serviços públicos (diretriz da Presidência do Conselho dos Ministros, de 22 de fevereiro de 1994) foi inspirado em uma metodologia de monitoramento baseado na regulação heterogênea dos entes prestadores de serviço, baseada na definição de padrões gerais de serviços, padrões específicos e avaliações periódicas operadas pelos entes prestadores de serviço e no recebimento das reclamações e intervenções orientadas à diminuição do distanciamento entre padrões de serviços e prestação efetiva. $^{15}$

Desse modo, parecem evidentes as finalidades do legislador que com tal instrumento ativou uma nova forma de palavra ou de protesto para os cidadãos/principais - que age mediante mecanismos de coordenação de voice giving. De fato, os cidadãos, também na ausência de alternativas concorrenciais para os bens ou os serviços fornecidos por uma organização pública, têm a possibilidade de fazer sentir diretamente as próprias instâncias, ou seja, exprimir um protesto com iniciativas individuais ou coletivas, voltadas a modificar as orientações, a lógica operacional e o estilo de ação de uma organização.

Para cada queda de nível das prestações dos serviços, os cidadãos, diretamente ou mediante pessoas ou grupos motivados a tutelar os seus interesses, podem escolher diferentes instrumentos idôneos para manifestar o protesto: reclamações e petições individuais e coletivas, apelos a órgãos de supervisão e controle dos quais dependem os entes em questão, mobilizações de opinião pública etc.

Exemplos de tais formas de palavra, além da carta dos serviços, já podem ser encontrados em institutos, tais como o ombudsman ou defensor cívico, ou em outros órgãos encarregados de canalizar as solicitações e as observações dos cidadãos, referentes ao funcionamento dos serviços públicos, direcionados a órgãos funcionalmente competentes, tais como órgãos de relações com o público (Urp).

A recente normatização, todavia, impõe a freqüente e periódica verificação do andamento das atividades (avaliação da eficácia e da eficiência por meio de indicadores de resultados paramétricos ou efetivos) ${ }^{16}$, com o objetivo de sentir o processo de correção, implícito no sistema de programação e controle descrito anteriormente.

De tudo o que foi afirmado até o presente momento, pode-se concluir que, com a carta dos serviços, o legislador confere aos cidadãos o papel de ator principal do processo de prestação dos serviços públicos. ${ }^{17}$ 
Os serviços públicos, por outro lado, sempre representaram uma das áreas nas quais o controle dos consumidores parecia mais fraca, pela ausência de um mercado concorrencial e pela insuficiência dos atuais sistemas de controle. Acrescenta-se a isso fundamentalmente a conscientização dos cidadãos de que o melhoramento da qualidade dos serviços realiza-se somente combinando a atividade de gestão com o impulso fornecido pela opinião pública e pelas associações de cidadãos. Parece evidente, portanto, que tal instrumento não nasce por acaso, mas é aprimorado no tempo, juntamente com a necessidade de conferir aos cidadãos a possibilidade de, por um lado, estimularem as empresas de serviço público a pesquisar novas soluções em grau de satisfazer as suas exigências mutáveis, e, por outro, de restabelecer a relação original cidadão/empresas de serviço público. ${ }^{18}$

Assim, a carta dos serviços configura-se como um sistema de acordo entre os cidadãos e os administradores das empresas de serviço público, ativado por instrumentos de voice giving (Fig. 4).

\section{Figura 4: A carta dos serviços públicos}

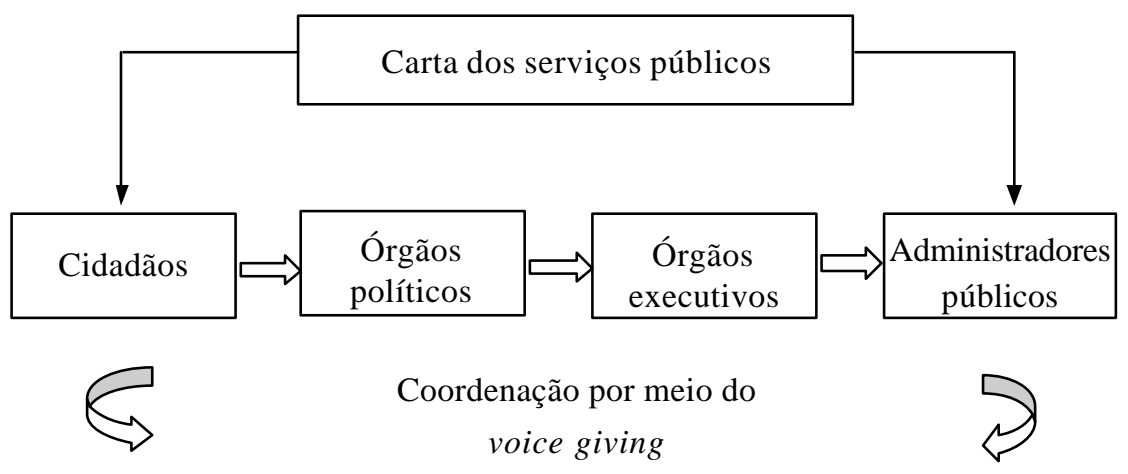

As suas vantagens consistem na possibilidade de utilização de instrumentos que restabelecem a relação original entre cidadãos e administradores públicos, favorecendo a melhoria da eficácia social da ação pública pela implementação de um sistema orientado a maiores trocas de informações.

Em particular, com referência aos instrumentos de adequação das exigências cidadãos/administração pública, deve ser dito que o Ministério da Função Pública está há algum tempo empenhado em um projeto que introduza mecanismos de ressarcimento nos casos de atraso por parte da administração pública; tudo isso com o objetivo de implementar um sistema de qualidade dos serviços públicos, visível, sobretudo, para o cidadão. Esse projeto está desenvolvendo a implementação do artigo 17 da lei sobre a descentralização administrativa, que prevê, além disso, a instituição 
de sistemas para a avaliação, com base em parâmetros objetivos dos resultados das atividades administrativas e dos serviços públicos. $\mathrm{O}$ grupo de trabalho deverá também individualizar indicadores de desempenho específicos que seriam correlatos às específicas atividades de cada administração.

Esse projeto enquadra-se num vasto programa de reforma da administração pública que tem como objeto o restabelecimento da relação entre os cidadãos e os administradores públicos por meio do lançamento de instrumentos de comunicação adequados. Com esse propósito, as redes cívicas e as cidades interligadas representam inovações voltadas a tornar mais funcional a relação em foco e, além disso, a superar as dificuldades dos canais comunicativos tradicionais, que são geralmente unidirecionais. O que é inovada radicalmente não é somente uma relação entre os cidadãos e o centro, ou entre o centro e os cidadãos, mas vem restabelecer também uma relação absolutamente inédita entre os cidadãos.

Ativa-se assim um processo de comunicação não somente vertical, mas também horizontal, no qual os cidadãos se comunicam por meio da mesma estrutura, sem mais a necessidade do centro. Em suma, também no interior das formas de comunicação, nas quais prevalecem elementos tipicamente estruturais de coesão coletiva e de identidade nacional, observase a presença de novas formas de comunicação fortemente desagregadas e com fortes elementos de desinteresse propriamente com relação ao elemento coesivo. Em outras palavras, a nova tarefa da administração pública é mediar as diversidades, ou seja, satisfazer as exigências específicas da sociedade, operando sob padrões que não são o fruto nem da mediação, nem da conciliação. Essa é a tarefa da carta dos serviços, que tem como objetivo abrir uma janela informativa sobre as ações da administração pública, de modo a ativar um processo de comunicação bidirecional, de modo a ser tanto ascendente e descendente, como horizontal e transversal.

Deve ficar claro que a carta dos serviços apresenta limites, que consistem na escassa capacidade de obter resultados em termos de economicidade dos serviços públicos, entendido como síntese do emprego eficiente dos limitados recursos disponíveis (medidos pelos custos) e do eficaz cumprimento das expectativas dos cidadãos. Se, de fato, a carta dos serviços permite uma recuperação da eficiência social pela comunicação, as dificuldades de adicionar uma recuperação da economicidade no interior do sistema em análise parecem ainda elevadas.

A carta dos serviços deveria favorecer a avaliação dos resultados conseguidos por um órgão público e sobretudo fornecer aos cidadãos a necessária consciência informativa para avaliar o avanço na realização dos objetivos pré-fixados, ou seja, fornecer uma clara definição dos parâmetros, das qualidades elementares a serem observadas e dos sistemas de indicadores mais idôneos a monitorá-los. 
Na realidade, o uso de indicadores de resultados para determinar a eficiência e a eficácia da ação pública é ainda pouco exigido nas empresas de serviços públicos. Sobre esse assunto, Baccarani, comentando o insucesso do Observatório da produtividade da Cispel, revelou que "foi perdida uma importante ocasião para dar início a um processo de mudança cultural, que se avistava em considerar o Observatório como um recurso fundamental à disposição de cada empresa para o conhecimento do setor no qual agiam. As empresas, pela intensificação das trocas relacionais de experiências e com base nessa rede cognitiva, teriam dado início seus processos de eficiência e eficácia nos processos" (Baccarani, 1995).

Como sustenta Borgonovi (1990), "a intervenção pública é mais vinculável a juízos de valor que as características intrínsecas da atividade concluída. (...) Da combinação variável de todos os elementos de verificação e de avaliação da performance, no plano dos resultados econômicos e não-econômicos obtidos, derivam estímulos bem diferentes para o desenvolvimento de uma administração inovadora e de diferentes mecanismos de avaliação de serviços prestados: por exemplo, no caso de empresas de serviços públicos 'únicas' em um país, a comparação pode ser feita somente com empresas de outros países, que podem ser influenciadas por variáveis institucionais, sociais e políticas bem diferentes".

Por outro lado, ainda não se alcançou, no setor da economia empresarial pública, um sistema satisfatório de classificação dos indicadores sociais coerente com o alcance das condições de economicidade, enquanto ainda prevalecem parâmetros e sistemas de medida não unificados em âmbito nacional (Panati e Golinelli, 1988).

A eficácia de um sistema de comunicação depende de uma verificação pontual do juízo dos cidadãos (pesquisas de opinião, de mercado etc.), por sua vez parametrizável de maneira objetiva somente pela sociedade (Censis, 1994).

Concluindo, tanto a realização insatisfatória de parâmetros sociais adequados às exigências de economicidade e coerentes com elas, quanto a inexistente ou escassa outorga à sociedade do controle externo da administração pública - seja por avaliação do grau de satisfação do principal público - seja, enfim, pela persistente assimetria informativa, pela qual o principal público não dispõe ainda de instrumentos cognitivos adequados à avaliação das atividades dos agentes públicos - constituem, em conjunto, elementos que não induzem a um juízo (pelo menos a curto prazo) positivo sobre a atual capacidade da carta dos serviços, para obter também resultados em termos de economicidade do serviço público no mesmo nível da eficiência social.

Portanto, é compreensível prever um sucesso parcial da carta dos serviços, pelo menos a médio prazo, em virtude do tempo necessário à assimilação dos princípios dos quais ela é portadora. Por outro lado, breve- 
mente a carta dos serviços poderá assumir uma função de estímulo à criação de um sistema de comunicação intra e interorganizacional que possa pelo menos criar as premissas para um acordo entre as instâncias dos cidadãos e dos administradores públicos.

\section{Notas}

Este trabalho foi publicado originalmente em italiano, sob o título Strumenti di voice giving nel raporto tra citadine e pubblica amministrazione: la carta dei servize, na revista Azienda Pubblica (n.1/2, XII, 1999).

** O presente trabalho foi desenvolvido no âmbito da pesquisa CNR 1997 "Evolução e perspectivas do controle direcional na administração pública”. Agradeço, portanto, ao professor Renato Mele e ao professor Marco Pellicano pela oportunidade de realizar este trabalho e pelas sugestões úteis que me foram dadas durante a realização do mesmo. A responsabilidade pelo teor deste documento é, todavia, exclusivamente pessoal.

1 O termo "usuários", apto a indicar os destinatários dos resultados da atividade de produção e fornecimento dos serviços, será substituído aqui pelo termo "cidadãos", ao nosso entender, melhor para enfatizar o papel ativo dos cidadãos, que é o de proprietário e não o de destinatário passivo dos serviços públicos. Do mesmo modo, não se empregará o termo "clientes" que, ainda que se associe a uma concepção econômico-empresarial mais moderna e ativa (comakers capazes de influenciar as condições de produção e fornecimento do serviço), adapta-se melhor a uma análise de marketing referente às empresas privadas, porque indica uma concepção de "centralidade do preço" e a avaliações de "conveniência estritamente econômica", não correspondentes às exigências dos cidadãos, para os quais o grau de satisfação se pode perseguir, mesmo nos casos onde a definição do preço não é central, e o serviço, para que seja satisfatório, deve ser fornecido quase gratuitamente.

2 Uma leitura teórica pode ser descritiva, prescritiva ou normativa. É descritiva quando consegue fotografar uma realidade específica; é prescritiva quando exprime ou implica escolhas mais ou menos apropriadas por parte de quem decide; por outro lado, a leitura normativa indica de maneira categórica, escolhas específicas a serem feitas por parte de quem decide.

3 O conceito de voice giving deve ser separado do conceito de voice, mecanismo fundamental de regulação da ação econômica (Hirschman, 1970): enquanto o termo voice indica o grupo de mecanismos de coordenação baseados na comunicação e no acordo direto entre as partes (Grandori, 1995), os instrumentos de voice giving são, por outro lado, ativados pelos sistemas de regras formais e/ou informais (institucionalização) como, por exemplo, pela carta dos serviços, típico mecanismo de institucionalização. Em particular, no âmbito da institucionalização dos sistemas de qualidade, a carta dos serviços manifesta uma elevada coação, referente à adesão à norma imposta pela força da lei e uma fonte de legitimação na aceitação legal (Ferrara, 1996: 229-230). Nessa perspectiva, a carta dos serviços "prevê a obrigação, para cada empresa de serviços públicos, de projetar e implementar um sistema de monitoramento e comunicação dos indicadores de 
qualidade do serviço oferecido aos cidadãos. Nesse caso, as empresas prestadoras são induzidas a utilizar metodologias específicas para análise, avaliação, melhoramento e atualização dos modelos qualitativos oferecidos, empenhando-se contextualmente para garantir ao cidadão procedimentos de gestão das reclamações" (op.cit.). A carta dos serviços, portanto, resulta em um instrumento de voice giving, enquanto favorece a "palavra de honra" por parte dos atores internos, e sobretudo externos, para comunicar exigências específicas.

${ }^{4}$ Segundo a escola de pesquisa "positivista", todas as relações podem ser relidas na ótica da teoria do agente principal. Assim, em alguns trabalhos, os órgãos centrais da administração pública são configurados no papel de principal, enquanto o papel do agente foi encoberto pelos entes periféricos.

${ }^{5}$ A dificuldade do cidadão em conseguir individualizar alternativas válidas aos serviços públicos evidencia a ausência de mecanismos de solução no sistema da administração pública. O presente trabalho, entretanto, limitar-se-á aos mecanismos de comunicação e de voice giving: isso porque, na Itália, o processo de empresarialização — que atualmente está caracterizando o setor dos serviços públicos — não parece ainda pronto para a introdução de mecanismos concorrenciais do tipo "real".

${ }^{6}$ Como recorda Mele (1994), isto favoreceu a passagem "de uma política de desavanço, como medida excepcional e transitória, a uma política do desavanço sistemático."

${ }^{7}$ Os custos da agência (controle, monitoramento e incentivos) representam modalidades específicas estratégicas para a redução das assimetrias informativas e, indiretamente, dos comportamentos oportunistas que caracterizam o modus operandi dos atores.

8 Do latim res, coisa; reificar significa conceber como concreto o abstrato, ou seja, considerar conceitos, categorias, idéias, relações abstratas na mesma medida dos conceitos.

${ }^{9}$ Nesse sentido, observa Bond (1992) que os comportamentos oportunísticos e egoístas não podem ser considerados a essência da organização como um todo; acrescenta Eisenhardt (1989) que a teoria do agente principal oferece uma "visão parcial do mundo".

${ }^{10}$ A teoria dos stakeholders é justificada na literatura tomando como base três tipos de contato: descritivo, instrumental e normativo. O primeiro procura descrever e eventualmente explicar características específicas e comportamentos empresariais; as justificativas instrumentais colocam em evidência a conexão entre a gestão dos stakeholders eo alcance dos tradicionais objetivos empresariais; o tipo normativo, por outro lado, procura interpretar as funções da empresa, incluindo a identificação das linhas morais ou filosóficas para as atividades e para a gestão empresarial. No presente trabalho, os três aspectos são considerados de maneira integrada; o primeiro contato é, de fato, tipicamente descritivo. O detalhamento descritivo tem suporte, todavia, no valor prenunciativo e instrumental com o qual se supõe a obtenção de resultados específicos quando se respeitam certas regras. Os primeiros estudos sobre o assunto devem-se a Freeman (1984); a leitura aqui utilizada é aquela de Donaldson e Preston (1995).

${ }^{11}$ Por exemplo, disponibilizando modelos de qualidade e eficiência do serviço, para avaliar as ações dos agentes públicos, até a inclusão de sanções verdadeiras e apropriadas, em forma de publicidade negativa, no caso em que não haja uma adequação aos modelos préfixados para os diversos serviços a serem prestados.

${ }^{12}$ A carta dos serviços foi introduzida por uma diretriz Ciampi, resultado de intensa atividade de estudo e pesquisa conduzida pelo Ministério da Função Pública, impulsionado pelo Ministro Sabino Cassese. Por isso mesmo, no início foi considerada um instrumento normativo de baixa coerção, porque foi elaborada diretamente pelo Presidente do Conselho dos Ministros, com o objetivo de traduzir os objetivos políticos, para a modernização da administração pública, em produção legislativa, evitando deste modo, iter legislativos longos e confusos. Em seguida, com a entrada em vigor do art. 2 da lei 1.279/95, a execução da carta dos serviços conheceu um vigor de atuação maior, ainda que 
não satisfatório. Tal diretriz estabelece as regras "pelas quais o fornecimento dos serviços públicos deve ser uniformizado progressivamente". Sobre o assunto, ver também Ferrara (1996).

${ }^{13}$ Tal análise é acompanhada de uma relação ilustrativa que enriquece seus conteúdos informativos, indicando os fatores externos que de algum modo podem influenciar a obtenção dos padrões pré-fixados, além dos métodos de avaliação utilizados para fixar ou rever os padrões e os indicadores a serem empregados para a mensuração dos resultados conseguidos (Testa, 1996).

${ }^{14}$ Para acompanhar a atuação da carta dos serviços públicos, foi instituído um comitê composto por três especialistas. Todavia, as indicações relativas às modalidades de controle são ainda insuficientes (Quais as verificações? Como desenvolvê-las?), e existem, ainda, problemas de implementação ligados à dimensão dos entes prestadores de serviço, à ausência de competências específicas e à escassez dos recursos disponíveis, sob a efetiva possibilidade de orientar a reestruturação organizacional implicada (Prosperetti, 1995; Mele e Pellicano, 1994).

${ }^{15} \mathrm{O}$ sistema italiano da carta dos serviços é inspirado no modelo britânico e é do tipo $a d$ imbuto: parte-se do nível mais geral (modelo governamental da carta dos serviços), para passar depois para a área setorial (transportes, energia, saúde) e, por fim, à realidade empresarial específica dos prestadores (Enel, Ferrovia do Estado etc.), que, eventualmente, diferenciará os próprios parâmetros com base territorial (regiões, distritos, áreas, etc.), respeitando os fatores de produção e prestação local específico (Mattiacci, 1997).

${ }^{16}$ No caso dos indicadores paramétricos, são individualizados indicadores preditivos do resultado final, que consentem uma avaliação dos processos administrativos (por exemplo, com o auxílio de indicadores das modificações do nível de eficiência nos processos de administração, é possível aos dirigentes utilizar tais informações para intervir com maior rapidez nas causas dos fenômenos ou ainda nos objetivos do controle, modificando o nível do resultado esperado). No caso dos indicadores efetivos, o controle sobre a direção percorrida focaliza-se na previsibilidade dos resultados, não supondo ações corretivas (Zangrandi, 1984).

17 "A concepção do século XIX, segundo a qual os usuários devem adequar-se ao que concede a administração pública, da sua posição de supremacia, já foi superada, e ao cidadão devem ser atribuídos instrumentos que permitam um controle sobre as ações da administração, fazendo com que a mesma responda de modo adequado, ou seja, rápido, correto e eficaz, às exigências de cada um". Extraído de uma entrevista concedida pelo Ministro Cassese em Il Tempo (1/1/1994) e à L'Unità (2/1/1994).

${ }^{18} \mathrm{O}$ cidadão pode produzir memórias, documentos e observações, para o melhoramento do serviço, aos quais os sujeitos prestadores devem responder prontamente, recebendo periodicamente, segundo as modalidades estabelecidas pela carta, a avaliação dos usuários sobre a qualidade do serviço em si (verificações efetuadas por amostra, subdividindo os usuários por segmentos — cidadãos, profissionais, empresas — por nível de satisfação/ insatisfação com os serviços, e assim por diante, para chegar a uma série de indicadores sintéticos do grau de satisfação dos usuários) (Pellicano, 1994). 


\section{Referências bibliográficas}

BACCARANI, C. (1995), "Qualità e aziende di pubblico servizio: la carta del cittadino", in Baccarani C. (a cura di), Saggi sulla qualità nell 'economia d'impresa, Padova: Cedam. Ensaios sobre a qualidade na economia da empresa, Pádova: Cedam.

Borgonovi, E. (1990), "La managerialità nell 'impresa pubblica", in L'Impresa, n.6.

Borgonovi, E. (a cura di) (1996), Principi e sistemi aziendali per le amministrazioni pubbliche, Milano: Egea.

Borgonovi, E. (1996b), "Le nuove frontiere dei servizi pubblici tra soddisfazione dell' utenza e tutela dell' interesse pubblico, in Sinergie, n. 41.

CAFFerata, R. (1993), La società per azioni pubblica, Milano: Franco Angeli.

Cafferata, R., Caselli L. (1995), "Proprietà e direzione nel governo delle imprese", in CAselli L., Le parole dell' impresa, vol. II, Milano: Franco Angeli.

Camuffo, A., Cappellari, R. (1996), "Le teorie neoistituzionaliste", in Costa G. Nacamulli, C.D. (a cura di), Manuale di organizzazione aziendale, vol. I, Torino: Utet.

CENsIs. (1994), La misura dell' azione amministrativa. Rapporto preliminare: concetti e metodi, Roma.

Donaldson, T., Prest on L.E. (1995), “Stakeholder aziendali”, in Sviluppo \& Organizzazione, Novembre/Dicembre n. 152.

Eisenhardt, K.M. (1989), “Agency Theory: An Assessment and Review”, Academy of Management Review, vol. 14, n.1.

Esposito, A. (1994), "La carta dei servizi pubblici per le imprese degli enti locali". Aziendaitalia, n.2.

FerRARA, M. (1996), Qualità e organizzazzione. Movimento della qualità e modelli di coordinamento, Torino: Giappichelli.

Freeman, R.E. (1984), Strategic Management. A Stakeholder Approach, Pitman.

Hill, C.W., Jones, T. M. (1992), “Stakeholder, Agency, Theory”. Journal of Management Studies. March.

Hirschman, A.O. (1970), Exit, Voice and Loyalty. Harvard University Press.

Jensen, M.C., Meckling, W. H. (1976), "Theory of the firm: managerial behaviour, agency costs and ownership structure", in Journal of financial economics, n.4.

MatTiACCI, A. (1997), "Carta dei servizi e managerialità pubblica: il caso Enel spa", in Economia e Diritto del Terziario, n. 2.

MeLE, R. (1993), Strategie e politiche di marketing delle imprese di pubblici servizi, Padova: Cedam.

(1995), "L'evoluzione degli studi economico-aziendali sull'impresa pubblica", in Melle R., Sicca L. (a cura di), Gli studi di economia d'impresa in Italia, Padova: Cedam.

Mele, R., Pellicano, M. (1994), "La carta dei servizi pubblici: problemi applicativi”, Aziendaitalia, n. 3.

Milanese, P. (1994), “Stakeholder Theory e Comunicazione d'Impresa”, Finanza, Marketing e Produzione.

Pellicano, M. (1995), “L'evoluzione della logica gestionale dell' azienda publica. Il differente orientamento alla misurazione dei risultati gestionali tra pubblico e privato", in MELE, R., Sicca, L. (a cura di), Gli studi di economia d'impresa in Italia, Padova: Cedam.

Pellicano, M. Storlazzi, A. (1996), "Uffici per le relazioni con il pubblico: una finestra per guardare dentro le p.a.", Aziendaitalia, n.3. 
Presidenza del Consiglio dei Ministri. (1993), Rapporto sulle condizioni delle pubbliche amministrazioni, Roma.

Dipartimento della funzione publica (1994), "Carta dei servizi pubblici. Proposta e materiali di studio", in Quaderni del Dipartimento della funzione pubblica, n. 5.

Prosperetti, L. (1995), "Con la "carta dei servizi' tutelati i diritti dei cittadini e degli utenti”, in II Sole 24-Ore del 1.3.1995.

Ross, S. (1973), "The Economic Theory of Agency: the Principal's Problem", in American Economic Review, n. 2.

TESTA, F. (1996), La carta dei servizi: uno strumento per la qualità nell 'università, Padova: Cedam.

ZuCKER, L. (1977), "The role of istituzionalization in cultural persistence." Amer Social Review, n.5, vol. 42. 
Revista do

Serviço

Público

Ano 51

Número 3

\section{Instrumentos de voice giving na relação entre os cidadãos e a administração pública: a carta dos serviços \\ Salvatore Esposito de Falco}

O sistema italiano da administração pública é caracterizado pela presença de uma tradicional distância entre os prestadores dos serviços públicos e os administradores das empresas públicas. A partir dessa realidade, o presente trabalho analisa a relação entre os cidadãos (entendidos como proprietários dos serviços públicos) e os administradores das empresas de serviços públicos, com o objetivo de observar e analisar o modo no qual os respectivos interesses divergem ou convergem entre si. Os enfoques de pesquisa utilizados foram os da teoria do agente principal e dos stakeholders mais adequados no sentido de destacar as discrepâncias de interesses entre as partes e a fornecer indicações instrumentais úteis para realinhar as relações estabelecidas. Em particular, a teoria do agente principal foi utilizada, limitando-se aos aspectos descritivos, para individualizar os atores e as relações recíprocas que caracterizam a organização interna da administração pública. Contudo, ao ter como objeto de análise as relações entre os cidadãos e os administradores públicos, a teoria do agente principal pareceu-nos muito limitante por ser fortemente vinculada à presença de uma visão plenamente reificada da empresa. Por outro lado, a teoria dos stakeholders, por conferir reconhecimento explícito aos interlocutores sócioeconômicos e institucionais, permitiu a individualização de instrumentos válidos ao exame das conexões existentes entre os atores (stakeholders). É nessa direção que a carta dos serviços foi analisada como um instrumento de comunicação induzida do tipo voice giving por meio do qual se pode restabelecer a relação original (direta) entre cidadãos e administradores das empresas de serviço público.

\section{Instrumentos de comunicación inducida (voice giving) en la relación entre los ciudadanos y la carta de servicios}

Salvatore Esposito de Falco

El sistema italiano de administración pública es caracterizado por la presencia de una tradicional distancia entre los prestadores de los servicios y los administradores de las empresas públicas. A partir de esta realidad, el presente trabajo analiza la relación entre los ciudadanos (entendidos como propietarios de los servicios públicos) y los administradores de la empresas de servicios públicos, con el objetivo de observar y analizar el modo en el cual los respectivos intereses divergen o convergen entre si. Los enfoques de investigación utilizados fueron los de la teoría del agente principal y de los interesados más adecuados en el sentido de destacar las discrepancias de intereses entre las partes y a proporcionar indicaciones instrumentales útiles para administrar las relaciones establecidas. En particular, la teoría del agente principal fue utilizada, limitándose a los aspectos descriptivos, para individualizar los actores y las relaciones recíprocas que caracterizan la organización interna de la administración pública. Sin embargo, al tener como objeto de análisis las relaciones entre los ciudadanos y los administradores públicos, la teoría del agente principal nos pareció muy limitada por ser fuertemente vinculada a la presencia de una visión plenamente objetiva de la empresa. Por otro lado, la teoría de los interesados por conferir reconocimiento explícito a los interlocutores sócio-económicos e institucionales, permitió la individualización de instrumentos válidos al examen de las conexiones existentes entre los actores interesados. Es en esa direción que la carta de servicios fue analizada como un instrumento de comunicación inducida del tipo "voice giving" por medio del cual se puede reestablecer la relación original (directa) entre los ciudadanos y los administradores de las empresas de servicio público.

Jul-Set 2000
Salvatore

Esposito de

Falco é doutor em pesquisa de Doutrinas

Econômico-

Empresariais

e Direção de

Empresas, no Instituto

Universitário

Naval de

Nápoles e

pós-doutorando na Faculdade de

Economia

da Universidade de Estudos de

Salerno. 


\section{Voice-giving instruments in the relationship between citizens and public managers: the portfolio of services}

Salvatore Esposito de Falco

The Italian public administration system is characterized by a gap between the public service providers and the managers of state-owned companies. Building on this assumption, this paper analyzes the relationship between the citizens (that is, the owners of public services) and the managers of state-owned companies, with a view to observing and analyzing the ways through which the interests of these parties may converge or diverge. The focus of the studies conducted was based on the principal agent theory, and that of the most appropriate stakeholders, in search of discrepancies of interest, as well as instrumental indicators of possibilities for the realignment of the relationships encountered. In particular, the principal agent theory was used, in its descriptive aspects only, to individualize stakeholders and their reciprocal relations, which is what characterizes the internal organization of the public administration. However, by focusing on the relationships between citizens and public managers, the principal agent theory appears to be limited, owing to its strong association with a vision of enterprises that is too concrete. The theory of stakeholders, in turn, by granting explicit acknowledgment to the social, economic, and institutional interlocutors, allowed the individualization of valid instruments for the examination of connections across stakeholders. In this context, the portfolio of services was analyzed as a voice-giving instrument of induced communication through which the original (direct) relationship between citizens and public service managers can be restored. 